588 Joumal des ticonomisles el des Eludes Humaines

Stephan,

I hape this is helpful. Feel free to emal any comments or questions.

Shor(a) music. Stlawu.edu

Steve Horwitz 


\title{
SPONTANEITY AND DESIGN IN THE EVOLUTION OF INSTITUTIONS: THE SIMILARITIES OF MONEY AND LAW*
}

\author{
Steven Horwitz ${ }^{\circ}$
}

\section{Introduction}

The observation that human action is mediated by social institutions comprises the beginning of any theory of social order. Differing explanations of the origins and functions of such institutions will lead to very divergent conceptions of the nature of social order and the role that human action and human reason can play in establishing it. In particular, those who ascribe the origin of social institutions to human design will see social order as the product of specific acts of human reason, while those who prefer evolutionary explanations of institutions will tend to view social order as deriving from the accumulated human wisdom and tradition embedded in institutions that have survived the process of social evolution.

The purpose of this paper is to compare the origins and functions of two specific social institutions, money and law, using an evolutionary approach that sees social institutions as the results of human action but not human design. More specifically, I wish to point out some striking similarities between two recent sets of literature relating to the role of government in the production of money and law. An evolutionary approach to institutions can provide a common framework for examining the theory of free banking ${ }^{1}$ and the more recent work on the nonpolitical provision of law. 2 The similarities between money and law as social

\footnotetext{
* The author would like to thank Peter Boctte, Mario Rizzo, Roger Koppl and other participants at the Austrian Economics Colloquium at New York University for comments on an earlier draft.

- Assistant Professor of Economics and Flora Irene Eggleston Faculty Chair, St Lawrence University, Canton, U.S.A.

1 See White-1984, Selgin-1988, Glasner-1989, Dowd-1989, Dowd-1992, and Horwitz-1992:.

2 See Barnett-1985, Benson-1990, 1992a, 1992b, and Solvasson-1993.
}

Volume 4, numéro 4, Décembre 1993, pp 571-587. 
institutions suggest that cross-fertilisation between the two sets of literature would be mutually beneficial. Below, I will sketch a non-formal theoretical explanation of the evolution of institutions and their role in facilitating social order, then explore how money and law might fit this explanation. I will also briefly discuss some examples of the apparent inability of both money and law to provide order and how such falures might relate to the question of the appropriate arrangements for their supply.

\section{Rules, Institutions and Social Order}

Explanations of social order are inevitably linked to discussions of communication. Any workable notion of social order must recognize that order involves some sort of complementarity in the expectations of social actors. This is the crucial element of Hayek's theory of social evolution. ${ }^{3}$ For social relationshipsto be "orderly," actors must 1) be able to form expectations about the actions of others that have some probability of being correct, 2) have some way of learning of the accuracy of their expectations, and 3) have some guidance as to how to correct them if they are mistaken. Ideally, social institutions can be the vehicles by which high degrees of social order are achieved. They can both communicate the information needed to form expectations and provide feedback to actors to help them adjust their expectations over time. Social institutions are, in this sense, social communication processes that enable actors to orient their behavior towards the expected behavior of others. ${ }^{4}$

Institutions perform this communicative function by constraining the actions of those who utilize them. Participants in social institutions are agreeing to abicle by the procedures that are part of the institutions in question. As a result, actors are able to form expectations about each other by observing each one's use (or non-use) of an institution. The way in which institutional processes are sets of rules that constrain behavior, and allow for more accurate expectation formation processes, can be seen by sketching out a general explanation of the evolution of social institutions.

Social institutions find their origins in some form of self interested behavior. Those actions that are more successful become adopted as rules of thumb by the acting individuals. The success of these actions will be noticed and imitated by others. As more imitation occurs, these rules of thumb will likely be increasingly successful because many such rules involve economies of scale in rule following. In other words, certain rules are more successful when there are more people using them. These so-called "network externalitics" can be seen in

3 Hayek-1973, 1989.

${ }^{4}$ Cr. Lachmann-1971, p. 50, who describes social institutions as "nodal points [that] ... relieve [us] of the need to acquire and digest detailed knowledge about sthers and form detailed expectations about their future actions." 
the use of a language or a telephone system. 5 The use of either is more effective when larger numbers of other people are doing the same.

The use or non-use of a social institution is an example of what Solvasson", following Vanberg and Buchanan, calls a "trust rule." The advantage of trust rules (such as "respect property") is that the benefits of following them are internalized to the followers, while the benefits of other rules, such as Vanberg and Buchanan's "solidarity rules" ("pay for one's viewing of public television") provide external benefits to non-followers. Because the benefits of trust rules are internalized, they can spread to larger groups than can solidarity rules. To the extent social institutions such as money and law rely on trust rules (exchange with money" or "follow the law"), they are likely to spread to, and be useful with, large groups.

As more actors follow a given rule, their expectation formation processes will become more accurate. As long as the act of following the rule is knowable by others, then actors can utilize the information conveyed by the rule-following behavior in forming their expectations. Benson's ${ }^{7}$ point that membership in a legal assurance group was a signal about reputable behavior can be generalized to show that participation in any social institution is also a signal about one's behaviors and intentions. ${ }^{\mathbf{8}}$ At some point, a large enough number of people follow particular rules of action so that quite reliable expectations can be formed and feedback to incorrect expectations can be disseminated. Then we might say that such rules of action have become social institutions.

Once social institutions emerge, they ease the difficulties involved with executing our particular purposes and plans. Social institutions have no real purposes of their own, other than to be participated in by actors so that they may more easily achieve their specific individual or collective purposes. Those who participate in social institutions are putting limits on the kind of possible actions they might take. Institutions are thus a form of collective self-constraining behavior. These constraints make our behavior more predictable to others and increase our chances of mutually coordinating our actions. ${ }^{9}$ In other words, social institutions and the rules that comprise them are forms of communication. As Schotter argues, the use of rules of action in a game-theoretic setting is "basically an information device that allows players to interpret that actions of their opponents."10

5 Warneryd-1990, p. 54 defines a situation involving network externalitics as "any systemic coordination problem with many people involved, where the attractiveness of a particular type of behavior wil! be frequency-dependent."

6 Solvasson-1993, p. 101.

7 Benson-1992a, p. 8.

8 It is assumed here that the evolution of social institutions corresponds to a indefinitely repeated prisoncr's dilemma game where reputation and reciprocity matter and can, as in Axelrod-1984, generate cooperative solutions.

9 Sce Warneryd-1990, p. 94: "Conventional behavior is necessary to resolve recurrent coordination problems."

10 Schotter-1986, p. 128. 
Importantly, social institutions are repositories of knowledge that we might otherwise find difficult, or impossible, to articulate. Frequently we are not even aware of the knowledge that such institutions impart to us, and only when someone acts in ways that grossly violate our sense of propriety do we realize that institutions involve these tacit expectations of the limits to action. 11 The fact that the range of permissible actions is frequently tacit makes it no less binding in that we expect that range to be respected.

It might also be the case that the range of actions expected from participation in an institution has little to do with the intentions of the first actors who began the process of emergence. Institutions take on a kind of "life of their own," which is dependent upon the various purposes of those who currently use institutionalized practices. As a result, institutions must be flexible enough to change with these differing purposes, yet still maintain enough coherence to still serve as guideposts. Insufficiently flexible institutions will be unable to adapt to new purposes for which they might be useful, while overly flexible institutions will be unable to provide the stability necessary to allow the formation of reasonably accurate expectations. Successful social institutions strike a balance between too little and too much flexibility.

Because institutions lead us to follow the rules that comprise them, they enable us to communicate in ways that direct linguistic communication alone does not. Social institutions are less constrained by physical space and time then is linguistic communication and therefore facilitate forms of communication that would otherwise be non-existent. Without social institutions and their ability to communicate, we would be unable to effectively coordinate our actions and any notion of order in social affairs would be problematic. We cannot directly know the purposes and plans of the multitude of anonymous others with whom we must interact to survive and prosper, and, as Langlois ${ }^{\mathbf{1 2}}$ summarizes them, social institutions serve as "interpersonal stores of coordinative knowledge ... [that] serve to restrict at once the dimensions of the agent's problem-situation and the extent of cognitive demands placed on the agent."

\section{Money as a Social Institution}

The exemplarly explanation of the spontaneous evolution of a social institution is the theory of the origin of money offered by Carl Menger. 13 when combined with a further exploration of how money, once evolved, facilitates social coordination, Menger's theory can be transformed into a more complete explanation of the social institution of money.

\footnotetext{
11 See Fuller-1969, p. 139: "There are some outcomes in human relations too absurd to rise to the level of conscious exclusion."

12 Langlois-1986, p. 237.

13 Menger-1892.
} 
Menger begins by assuming a barter economy where consumption goods are traded directly for other consumption goods. Assuming even limited specialization in production, it follows that actors will have excess supplies of the good they produce and will want to trade these for the production of others. The problem a given trader faces is finding other traders who both produce what he wants and wants what he produces. These barter exchanges will be easier to execute if actors can bring to market goods that they think others will find to be desirable. Even those who produce goods that are not very easily saleable could trade them for somewhat more saleable goods and then trade those for the things they ultimately desire. Because of the problems posed by differing degrees of saleability, a series of exchanges for goods of increasing saleability, leading to the ultimately desired good, may be an easier way of fulfilling wants than hoping for a direct match between the originally possessed good and the one ultimately desired.

Menger ${ }^{\mathbf{1 4}}$ argues that discovering which goods are more saleable "never arises in every part of a nation at the same time." As these indirect exchanges take place, those who successfully use them to acquire what they want will demonstrate the relative saleability of the goods they use. These processes of indirect exchange generate the needed knowledge of saleability. In addition, observation and imitation provide ways of communicating this information without actors needing to be consciously aware of what is happening. As successful indirect exchange occurs, others imitate that success by using those intermediate goods in their own exchange sequences. This imitative process begins to narrow the range of goods used as intermediate objects of exchange by spreading knowledge of which goods are relatively more saleable. As this convergence occurs, actors begin to more successfully coordinate their actions, as the shrinking number of intermediate goods makes it easier for actors to form expectations about which goods will be needed to execute indirect exchanges.

The imitative behavior not only spreads the use of specific intermediate goods, it also enhances their saleability. Now the intermediate goods are being demanded by both the original users and the imitators, making them more saleable and more suitable as media of exchange, thus heightening the success of those who use them. This process of imitation and convergence continues until some very small number (usually one) of goods emerge as the most saleable, and become generally accepted media of exchange, or money. Money, according to Menger, is not imposed on a population by fiat, but emerges, as it were, from below, out of the preferences and actions of actual traders who use it. 15

Once money emerges, it becomes one half of virtually every market exchange. As such, it is pervasive in the market and underlies the entire process of economic calculation and coordination. In particular, the use of money symbolizes a form of trust in other traders and the social order. This relationship between

14 Menger-1892, p. 249.

15 Cf. Mises-1966, p. 407, "only the conduct of exchanging people can create indirect exchange and money." 
money and trust and its implications for money's role as a social institution have been explored in clepth by the sociologist Georg Simmel in The Philosophy of Money ${ }^{16}$. Simmel argues that the use of money and the corresponding expansion of economic relations,

"eventually produce in the enlarged, and finally international, circle the same features that originally characterized only closed groups; economic and legal conditions overcome the spatial separation more and more, and they come to operate just as reliably, precisely, and predictably over a great distance as they did previously in local communities."17

By extending social trust, the use of money enables us to coordinate our behavior with anonymous others who are beyond the limits of the spoken or written word and face-to-face contact. 18 The fact that people choose to trade using a given money indicates their trust in the willingness of others to accept it and base their expectations on it.

For Simmel, the implication is that money is a kind of tool. Rather than being an end in itself, money becomes a universal means for individuals to pursue the ends they desire. Simmel ${ }^{19}$ points out that money, like all social institutions, enables us to "attain ends for which [our] personal abilities would never suffice." Money facilitates this coordination process by constraining us to tracle using the specific medium of exchange that is socially acceptable. A monetary economy virtually rules out barter exchanges, even though they might be "easier" in specific instances. ${ }^{20}$ By following the trust rule of "trade using money" we send signals to others that enhance our long run ability to achieve our ends.

Because we all use the medium of exchange to trade for our ultimate ends, social order is enhanced. Successful exchanges are easier to execute because we reduce the transactions costs of finding desirable exchange opportunities. These saved resources, combined with money's ability to serve as a point of reference for economic calculation, increase productivity and social wealth.

\section{The Legal Order as an Institutional Framework}

While arguing that money emerges through a long and continuous process of evolution is not overly controversial, making the same argument for law is much more difficult in a century dominated by legal positivisp. Legal positivism

16 Simmel-1978.

17 Simmel-1978, p. 182.

18 Compare Benson-1992a, p. 5 on the evolution of law: "Under certain conditions, the social contract underlying the production of law can be achieved through the process of indiviclual agreements with the resulting rules spreading to other members of the relevant (but perhaps geographically dispersed) collective group if they are useful rules."

19 Simmel-1978, p. 211.

20 See Oh-1989 for a discussion of how optimality in the use of money might still leave room for barter exchanges if the transictions costs of some monetary exchanges are too high. 


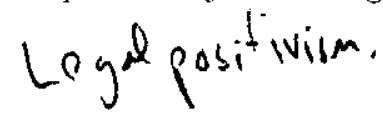

argues that whatever statutes are passed by a recognized political authority should be considered law, independent of how these statutes cohere into the byoadey framework of society or of how they relate to the actions of the individuals bound by them. By contrast, there is the work of other legal theorists, notably Lon Fuller 21 , who argues that the term law should refer to "the enterprise of subjecting Thuman conduct to the governance of rules," and Bruno Leoni ${ }^{\mathbf{2 2}}$ who sees judgemade law as a form of collective self-constràint that only works if it emerges from the actions of the parties to disputes. Fuller's definition embodies both the notion of law as an institution with a function (rather that a mere set of decrees) and the conception of governance as implying some sort of consistency or coherence among the rules. Fuller's explanation of the origin and function of the law also parallels Menger's theory of the origin and function of money.

Fuller's explanation of the emergence of customary law and the law of contract is particularly notable for its evolutionary perspective. $\mathrm{He}^{23}$ defines customary law as "consisting of the reciprocal expectations that arise out of human interaction ... lit is] a langnage of interaction." $\mathbf{2 4}$ Individuals begin to deal with each other in face-to-face situations. Even in the absence of written contracts, certain behavioral norms will emerge through repeated interaction as people attempt to mutually coordinate their behavior. If the interaction is thought to be mutually beneficial, both parties will have incentives to behave in ways that each other expect in order to facilitate the interaction. If, over time, certain behavioral patterns emerge so strongly that individuals begin to form expectations based upon them and spread them to other interactional contexts, then we have the emergence of customary law. As Fuller points out, normally we reserve the term "law" for sets of rules that are imposed from outside a given two-party relationship. However, if law is to be understood as the enterprise of subjecting human conduct to the governance of rules, the expectations arising from repeated two-party interactions could legitimately be seen as law. Once such expectational practices are transferred to multiple situations, then clearly we have what we more traditionally think of as law.

As in Menger's story of the origin of money, the emergence of law is an unintended consequence of self-interested behavior. The two parties to the relationship want only to be able to accurately expect the behavior of the ather. They need not have the intention of creating a precedent for other such relationships. However, if certain practices or rules are successful in generating reliable expectations, they will tend to be imitated and spread in the same way as in our gencral explanation of institutions and Menger's theory of money.

Eventually, we will be left with a set of more or less coherent practices that we can call law. Analogous to a "generally accepted medium of exchange," we might call law a "generally accepted set of rules for interpersonal interaction."

21 Fuller-1969, p. 106.

22 Leoni-1972, p. 3.

23 Fuller-1981, p. 176, emplasis in original.

24 Others have argued that money is abin_onaguga in this way, see Warneryd-1990 and Horwitz19) $2 \mathrm{~h}$. 
The imitative process turns purely self-interested customs into social ones that enable an infinite number of anonymous others to act effectively by utilizing the emerging and evolving customary law.

In the same way that Menger's story implies that money must emerge through actual exchange and cannot be imposed from without, so does Fuller's explanation of customary law insist that true law arises from the interaction of real social actors. Both money and law come from the bottom up: "Only those who know those interests intimately, who can feel their way toward the best reciprocal adjustment of them, are competent to find a truly satisfactory solution". 25 As Vihanto $^{26}$ points out in his discussion of legal institutions, they "are usually first understood and approved by only a small number of ... individuals" before spreading to the population as a whole. This also suggests an evolutionary origin for such practices and that their continued evolution is, as Vihanto stresses, a process of discovery.

Fuller argues further that if the law is a codification of "reciprocal interactional expectancies," then it must derive from the meaning that parties attach to their contracts. But where does this meaning come from? Fuller ${ }^{27}$ answers that "courts may imply a contract entirely from the conduct of the parties; though no verbal exchange has taken place ..." Leoni also points out that the fuction of judges is to discover the meaning that the various parties attach to their actions:

"the whole process can be described as a sort of vast, continuous, and chiefly spontaneous collaboration between the judges and the judged in order to discover what the people's will is in a series of definite instances. With repeated use these interactional expectancies become widespread enough to rise above the local contexts from which they originated and they become law." 28

Fuller ${ }^{29}$ also points out that the expectancies that customary law gives rise to are not, and cannot be fully articulated. Often the most important expectations that are part of any human action are those we never pause to consciously articulate. Fuller ${ }^{\mathbf{3 0}}$ borrows Wittgenstein's example of a mother who tells a babysitter to "teach my child a game" and returns to find that the sitter has shown the child how to duel with kitchen knives. Clearly that game was not one that the mother had in mind, yet she never consciously paused to consider that her words would be interpreted that way.

In the same way, parties to an interaction (or an explicit contract) will be bound by tacit limits as to what each can reliably expected to do. As parties in interactional relationships converge toward mutally acceptable rules of conduct, they will be unable to consciously consider and eliminate every feasible behavior

\footnotetext{
25 Fuller-1981, p. 210.

26 Vihanto-1993, p. 66.

27 Fuller-1981, p. 176.

28 Leoni-1972, p. 21.

29 Fuller-1981, p. 220.

30 Fuller-1969, pp. $138-9$.
} 
the other might take. The bounds of the consciously explicable will be related to the specific context of the original relationship. However, similar contexts will likely produce similar explicit expectations, and the tacit limits that underlie them will become part of expectation formation processes when the explicit customary relationships are codified into law. Like money, the law becomes a communication process that provides knowledge beyond that which can be explicitly put into language.

Another way of conceiving the function of law is to see it as a set of guideposts for human action. Roberta Kevelson ${ }^{\mathbf{3 1}}$ sees the legal system as a system of signs and analyzes it using the method of semiotics (the interpretation of signs). For Kevelson 32 the system of signs that comprises the legal order is one of a number of "verbal and non-verbal sign systems" that human beings have evolved to effect social coordination. The law delimits actions deemed to be appropriate, providing actors with points of (tacitly) agreed upon mutual contact which assist in forming accurate expectations. As Hayek argues of existing laws:

"they give rise to expectations that guide peoples' actions, and what will be regarded as binding will therefore be those practices that everybody counts on being observed and which thereby have become the condition for the success of most activities".33

In much the same way that actors in a barter economy would find it quite difficult to pursue their own purposes and plans because the coordination induced by the use of money would be absent, so would actors find social coordination difficult in a world without law, as game-theoretic attempts to leap out of the Hobbesian jungle have illustrated. Money, by facilitating economic calculation, also enables us to select out the economically feasible from the bewildering array of potential production processes. Similarly, law, by offering an agreed upon set of rules of action and promulgating accurate expectation formation processes,

"rescue[s] man from the blind play of chance and...put[s] him safely on the road to purposeful and creative activity".34

\section{Money, Law and the Market}

If the origins and functions of money and law are so similar, there might also be similarities in the way in which both are supplied in modern societies. What is striking about both institutions is that they are normally two-of-the first ones whose direction is presumed to be most efficientl) performed by the state. As Bell points out:

\footnotetext{
${ }^{31}$ Kevelson-1988.

32 op. cit. p. 4.

33 Hayek-1977, p. 97.

34 Fuller-1969, p. 9.
} 
"Money and law developed in parallel fashion ... medieval Europeans enjoyed competition in currencies and legal systems until monarchies took over both fields. And state monopolies in money and law now present common hazards". 35

Historically, any suggestion that either money or law be provided by voluntary exchange in a market would have been seen as suspect. However, this prejudice is slowly changing. An examination of the literature on the potential benefits of depriving the state of its monopoly over the production of money and law can help to see whether the ideas developed above can add to the arguments of both literatures.

That the production of both money and law has quickly become the prerogative of the state is not a coincidence. By taking over both institutions, governments are able to use them as sources of revenue. Whte governments themselves may benefit from these methods of finance, $t h$ that they are less politically costly than direct taxation, it is questionable whether state provision of money and law is more, or even equally, likely to induce the same degree of social order as would private provision.

As historians of banking have shown, the origins of central banks have invariably been linked to the revenue needs of governments, particularly in times of war. ${ }^{36}$ Rather than attempt to raise the needed funds by direct taxation, or incur the expense of debt, governments have simply directly taken over, or otherwise manipulated, banking systems to do the job. Most obviously this could be accomplished by the state claiming a monopoly right to produce currency and then using newly produced currency to purchase supplies. Other means would include giving a monetary authority the special right to conduct open market operations and buy up government debt or by creating regulations that force banks to buy up government debt as a condition for conducting specific banking operations. ${ }^{37}$ When governments have used regulations to guide bankers into revenue-raising activities, banks have historically found ways around the law, leading to demands for further regulation and eventual centralization. The virtual disappearance of competing currency producers across the world, despite their one time proliferation, is evidence for this process. 38

As Bruce Benson's ${ }^{39}$ study of the law illustrates, it too was once provided by voluntary arrangements between parties only to be slowly taken over by governments in order to raise revenue. ${ }^{40} \mathrm{He}$ clescribes the change in English law brought on by early Norman rule:

\footnotetext{
35 Bell-1991/92, p. 1.

36 See, for example, Smith-1990 and Glasner-1989.

37 The former power was given to the Fed as patt of the Banking Act of 1935 , while the latter was a part of the U.S. National Banking System (1863-1914). The NBS required national banks to buy up government bonds as a condition of currency issue. Legislators were explicit in using this tegulation as a way of raising revenue for the Civil War.

38 See Schuler-1992 for a discussion of the numerous countries that historically had at least partial forms of liee banking for some period of time.

39 Benson-1990.

${ }^{40}$ See Bell-1991/92 and Benson-1992b for a more detailed discussion of the issues below.
} 
"One of the earliest and most significant changes the Normans made in English law was replacing the old restitution-based system... with a system of fines and confiscations along with corporal and capital punishment." 41

Later on, in the 1100 s, King Henry II further extended the state's role in judicial decisions by introducing what we now know as the distinction between civil and criminal law. Prior to this time, the king's direct involvement was limited to disturbances against the king's person or castle, known as "disturbing the king's peace." However, Henry extended this concept to almost any disturbance that occurred in the land politically controlled by the king. As Benson describes it:

"These offenses came to be known as "crimes," and the contrast between criminal and civil causes developed, with criminal causes referring to offenses that generated revenues for the king or the sheriffs rather than payment to the victim", $\mathbf{4 2}$

The whole notion of a crime "against the state" derived out of this extension of royal power designed to redirect the payment of monetary restitution to the state rather than the victim. Again, this process parallels the progressive politicization of money. Solvasson's study $\mathbf{4 3}$ of the stateless order of ancient Iceland parallels Benson's view of medieval England. Solvasson explains how the decentralized choices of individuals in ancient Iceland generated successful legal institutions that are fairly similar to those of medieval England. He also documents how this spontaneously evolved system began to fall apart with the arrival of state intervention. Solvasson places somewhat less emphasis on the revenue-raising interest of the state per se than he does on the rent-seeking activities of actors outsicle the political process. Various actors within the Icelandic system stood to gain if the state became more involved in the legal system and such actors actively sought that result. Prior to its fall, the Icelandic legal system was a further illustration of how a spontaneously evolved legal order can better generate social order than one consciously designed from the top down.

As a result of piecemeal attempts to squelch the spontaneous process of legal evolution, modern legal institutions and procedures reflect not the conscious design of an omniscient lawgiver, but are rather the unintended consequences of state intervention. More specifically, as the state became more and more involved in the law, it created urintended consequenses that frustrated its original purposes and required further intervention--In a description that could equally apply to the history of monetary institutions, Benson says of this process:

"The explanation lies in forces set into motion hundreds of years earlier...Each change initiated by government created problems that required additional change. When law is deliberately designed, whether well-intended or not, there will always be manifestations that the

\footnotetext{
41 Benson-1990, p. 47.

42 op. cit, p. 53.

43 Solvasson-1993.
} 
designers did not anticipate. When some of those manifestations prove to be undesirable, new rules are designed, which will also have unanticipated consequences". 44

For example, the development of jails was a way to punish those who did not pay their fines and the whole notion of rules of evidence and the right to defense counsel developed in response to kings using tax financed prosecutors in criminal cases. 45 On the monetary side, one can view the Federal Reserve sysm as a response to the unintended undesirable consequences of the National Banking System's regulations, themselves responses to the failures of the various regulations of the so-called "Free Banking Era." 46 These various unintended consequences created the problems that called forth further regulations and further unintended consequences. The complexities and apparent contradictions of both modern monetary and legal institutions are driven by political purposes, rather than being spontaneously evolved solutions to underlying coordination problems.

The problem created by the historical course of events is the current assumption that the state must be the source of monetary and legal order. However, as Menger and the free banking literature argue, money in fact grows out of the practices of traders and the state can only give sanction to what already has become accepted as a medium of exchange. Both Fuller and Benson see law in a similar light. To Fuller, the mistake of legal positivism is to see law as being "an instrument of social control" and thus identify law with whatever the state decrees. ${ }^{47}$ Fuller argues that this definition necessarily abstracts from the questions of why law develops and exists, and how it does so. Like G. F. Knapp's famous "State Theory of Money" $\mathbf{4 8}$ which argued that money is whatever the state defines as money, we might refer to the positivist conception of law as a "State Theory of Law." 49 As the arguments above indicate, both theories are problematíc because both forgo any explanation based on the functions of the institutions in question.

\section{Market Responses to Government Failure}

More evidence for the parallels between the spontaneous origins of money and law comes from examining periods of crisis in the state control of both institutions. In the crises that occurred during the U. S. National Banking System,
44 Benson-1992b, p (66.) -
15 Op. cit, pp. $62-76$

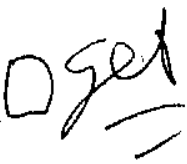
46 In particular, one can view the National Currency Act that created the National Banking System as an attempt to create a uniform national currency to replace the state-based currencies of the Free Banking Era. Law against interstate banking, as well as restrictions on the assets that were permitted to be held against currency issues, were responsible for the problem that the federal government was trying to solve with the National Banking System.
47 Fuller-1969, pp. $106 \mathrm{ff}$.
48 Knapp-1924.
49 Keynes-1930, pp. 4-5 also accepts Knapp's discussion, at least for modern economies. 
the national banks were unable (due to various revenue-raising regulations) to create sufficient currency to meet public demands. In response, the banks themselves came up with a number of different ways of evading the law and providing forms of currency for public use ${ }^{\mathbf{5 0}}$ For example, banks used negotiable, round-denomination cashier's checks that circulated by repeated endorsement or were made payable to the bearer. Some firms paid workers in negotiable rounddenomination checks (a $\$ 35$ wage payment might be made in $3 \$ 10$ checks and $5 \$ 1$ checks) written off the firms' bank accounts. In addition, numerous saleable, yet officially non-money, objects served as money including grain purchase orders and streel car tickets.

In the panics of both 1893 and 1907 , these spontaneously generated moneys quickly emerged in the face of the failure of the government-regulated monetary system. In almost all cases, actors were not concerned with the global effects of their actions, they were simply developing solutions to the contextspecific problems they faced in making exchanges. As in the theoretical explanation earlier, these beneficial practices were quickly noted and imitated, and spread rapidly among the money using public. Despite the fact that these currency substitutes were clearly illegal and carried no form of government assurance, they were quickly adopted as money and served their role well. The losses to users of these currency substitutes were negligible in both panics. The overall effect was that these illegal and privately produced currency substitutes effectively restored monetary order where state provision had created chaos.

Benson provides some similar examples from legal history. $\mathrm{He}^{\mathbf{5 1}}$ describes San Francisco's experience with vigilante justice when the citizens lost confidence in the city's ability to enforce the law in the late 1840 s and early 1850 s. In the spring of 1851 a committee was formed to shadow the official legal structure and "assist city officers in discovering and apprehending criminals".52 For several months the committee arrested and tried suspected criminals. Rather than the chaos and violence one might expect from vigilantes, the committee, according to Benson and his sources, acted in moderation and with genuine justice. During the hundred days of their operation, they made 91 arrests, hanged four men, banished several others from the city and called for the deportation of a number of others, all after trials took place. 53 Benson also reports that 41 of the 91 were discharged after being found innocent. This was hardly vigilanteism in the colloquial sense. To the contrary, according to reports, during the period the committee was in existence, the city returned to relative peace and quiet.

Five years later, when the city government was riddled with a corruption scandal, the committee reformed to enforce the laws they felt the corrupt police department was again neglecting. Once again reports indicate that the committee conducted itself reasonably and was successful in deterring and eliminating

\footnotetext{
50 These episodes are explored more fully in Horwitz-1990 and Horwitz-1992a, chapter 4, which provide the sources for the examples below.

51 Benson-1990, pp. 315-21.

52 lbid., p. 317.

$53 \mathrm{lbid}$, p. 318
} 
ongoing crime. Much in the same way that the currency substitutes restored monetary order, so did the legal substitute of the vigilante committee restore legal order. Bell argues that:

"By demonstrating wisdom and impartiality private courts can offer for sale judgments that people respect [just as] people will only respect the currency of [free] banks that demonstrate adequeate reserves and good management." 54

Benson's conclusion concerning the vigilante committees is worth repeating:

"Generally, vigilante movements involved law-abiding citizens enforcing the law and re-establishing order. Those who view a vigilante movement under any circumstances as an example of lawlessness are victims of one of the most serious flaws in the argument that law and its enforcement must be monopolized by government. When law is only what government says it is, then vigilantes are always lawless and deserve to be 'put down by force'." 55

By contrast, if law is seen as a set of rules for ordering human interaction, then "vigilantes" may be more law-abiding than the state. Legal relationships are reciprocal, as Fuller insists, and the producers and enforcers of law have an obligation to those who utilize it to proceed in fair and reasonable ways. The etymological relationship between "vigilante" and "vigilant" is the source of Benson and Fuller's point: users of legal institutions must remain vigilant as to the duties of those who "operate" such institutions and be willing to enforce the implied obligations if need be.

One might well ask why state run legal institutions are likely to break down. The answer is parallel to explanations of why government central banking has failed, namely that the aims of government central banks have little to do with producing a money that can serve as an effective social institution for guiding human behavior. Because the knowledge needed to design accurately both money and law is both tacit and voluminous, and cannot be marshalled in a central authority, political actors find attempts at rational design unsuccessful and turn to pursue their more self-interested purposes. Leoni 56 explicitly argues that the problem facing a legislator trying to create law whole cloth is a version of the problem facing a central economic planner. Leoni says of the Mises-Hayek epistemological critique of planning that it is

\footnotetext{
54 Bell-1991/92, p. 9, however, does claim that one advantage free banking theory has is that it can argue that free banking systems will bring markets closer to the ideal of general equilibritm, while no parallel ideal exists in legal theory. While free banking does penatize banks which deviate from monetary equilibrium, there is no necessary reason to think this tendency is toward general equilibrium also, particularly in the technical sense used by economists. In general, arguments for the market that rely on tendencies to equilibrium are quite problematic (see Boettke/Horwitz/Ptychitko1986) and it is legal theory's strength not its weakness that it has forgone an unachievabie ideal as its standard of success.

55 13enson-1990, p. 320

56 Leoni-1972, p. 18
} 
"a special case of a more general realization that no legislator would be able to establish by himself...the rules governing the actual behavior of everybody in the endless relationships that each has with everybody else."

Peter Aranson $\mathbf{5 7}$ makes a similar argument against the Coasean or Posnerian judge who must render the appropriate legal decision based on a weighing of the economic costs and benefits of each alternative, "Any court that seeks to calculate such cost ... is engaged in a central planning, economiccalculation and direction activity. And so all of the Austrian and L. S. E. critiques fully apply." When faced with the impossible task of consciously choosing the institutions or practices that will promote economic, legal, or social order, political actors will fall back on decisions that reap them political gain.

As a result of these epistemological problems government produced law and money has taken a direction that has progressively less to do with "the enterprise of subjecting human conduct to the governance of rules," or providing a generally accepted medium of exchange, and more to do with serving the selfinterest of legal-political actors and government's need for resources and power.

\section{Conclusion}

Social institutions evolve as crystallized sets of rules that have proved to be successful for achieving our different purposes and plans. Money and law in particular are examples of social institutions that have emerged to serve these purposes. If the "purpose" of both money and law is to serve as universal means for the success of numerous different human actions, then the ways in which both are produced should ensure the monetary and legal rules and institutions that result will bear some relationship to the purposes and plans of the actors that make use of them. Politically monopolizing money and law leaves them unable to best serve as frameworks for social order and subjects the production of both to the purposes of politicians and those with sufficient weight to influence them, rather than to the needs of individual actors who rely on both for guidance in a world full of uncertainty and constant change. The results of increased politicization and monopolization will be a loss of the signalling function of both institutions and a corresponding clecline in social order. As scholars in both monetary economics and legal theory continue to explore the theoretical and policy issues surrounding these questions, they should take advantage of the important similarities between the two fields.

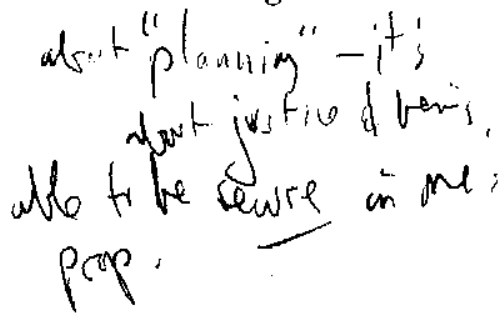

57 Aranson-1992, p. 305. 


\section{References}

Aranson, P. (1992), "The Common Law as Central Economic Planning", Constitutional Political Economy, Vol. 3, $\mathrm{N}^{\circ} 3$, Fall.

Axelrod, R. (1984), The Evolution of Cooperation, New York, Basic Books.

Barnett, R. (1985), "Pursuing Justice in a Free Society, Part One: Power vs. Liberty," Criminal Justice Ethics, Vol. 4, Winter/Spring.

Bell, T.W. (1991/92), "Polycentric Law", Humane Studies Review, Vol. 7, $\mathrm{N}^{\circ} 1$, Winter.

Benson, B. (1990), The Enterprise of Law, San Francisco, Pacific Research Institute for Public Policy,

Benson, B. (1992a), "Customary Law as a Social Contract: International Commercial Law", Constitutional Political Economy, Vol. 3, N ${ }^{\circ} 1$, Winter.

Benson, B. (1992b), "The Development of Criminal Law and its Enforcement: Public Interest or Political Transfers?", Journal des Economistes et des Etudes Humaines, Vol. 3, $\mathrm{N}^{\circ} 1$, March.

Boettke, P., Horwitz, S. \& Prychitko, D.L. (1986), "Beyond Equilibrium Economics: Reflections on the Uniqueness of the Austrian Tradition", Market Process, Vol. $4, \mathrm{~N}^{\circ} 2$, Fall.

Dowd, K. (1989), The State and the Monetary System, Oxford, Philip Alan. Routledge.

Dowd, K. (ed.) (1992), The Experience of Free Banking, London,

Fuller, L.L. (1969), The Morality of Law. New Haven, Yale University Press.

Fuller, L.L. (1981), The Principles of Social Order. Durham, Duke University Press.

Glasner, D. (1989), Free Banking and Monetary Reform, Cambridge, Cambridge University Press.

Hayek, F.A. (1973), Law, Legislation, and Liberty, Vol. 1, Chicago, The University of Chicago Press.

Hayek, F.A. (1989), The Fatal Conceit: The Errors of Socialism, Chicago, The University of Chicago Press.

Horwitz, s. (1990), "Competitive Currencies, Legal Restrictions and the Origins of the Fed: Some Evidence from the Panic of 1907", Southern Economic Journal, Vol. $56, \mathrm{~N}^{\circ} 4$, January.

Horwitz, S. (1992a), Monetary Evolution, Free Banking and Economic Order, Boulder, Westview Press.

Horwitz, S. (1992b), "Monetary Exchange as an Extra-Linguistic Communication Process", Review of Social Economy, Vol. 50, $\mathrm{N}^{\circ} 2$, Summer.

Kevelson, R. (1988), The Law as a System of Signs, New York, Plenum Press.

Keynes, J.M. (1930), A Treatise on Money, Vols. 1 and 2, London, Macmillan and Company.

Knapp, G.F. (1924), The State Theory of Money, London, Macmillan and Company. 
Lachmann, L.M. (1971), The Legacy of Max Weber, Berkeley, The Glendessary Press.

Langlois, R. (1986), "Rationality, Institutions, and Explanation", in Langlois, ed. (1986).

Langlois, R. (ed.) (1986), Economics as a Process: Essays in the New Institutionalist Economics, Cambridge, Cambridge University Press.

Leoni, B. (1972), Freedom and the Law, Los Angeles, Nash.

Menger, C. (1892), "On the Origin of Money", Economic Joumal, $\mathrm{N}^{\circ} 2$.

Mises, L. von. (1966), Human Action: A Treatise on Economics, Chicago, Henry Regnery.

Oh, S. (1989), "A Theory of a Generally Accepted Medium of Exchange and Barter", Journal of Monetary Economics, Vol. 23, $\mathrm{N}^{\circ} 1$, January.

Schotter, A. (1986), "The Evolution of Rules", in Langlois, ed., (1986). (1992).

Schuler, K. (1992), "The World History of Free Banking", in Dowd, ed.,

Selgin, G. (1988), The Theory of Free Banking: Money Supply Under Competitive Note Issue, Totowa, N.J., Rowman and Littlefield.

Simmel, G. (1978), The Pbilosopby of Money, Boston, Routledge. Liberty Press.

Smith, V. (1990), The Rationale of Central Banking, Indianapolis,

Solvasson, B. (1993), "Institutional Evolution in the Icelandic Commonwealth", Constitutional Political Economy, Vol. 4, $\mathrm{N}^{\circ} 1$, Winter.

Vihanto, M. (1993), "Social Contract, Natural Law, and Spontaneous Evolution: An Austrian Perspective", Journal des Economistes el des Etudes Humaines, Vol. $4, \mathrm{~N}^{\circ} 1$, March.

Warneryd, K. (1990), "Conventions: An Evolutionary Approach", Constitutional Political Economy, Vol. 1, $\mathrm{N}^{\circ} 3$, Fall.

White, L.H. (1984), Free Banking in Britain, Cambridge, Cambridge University Press. 